\title{
Powdery Mildew of Rudbeckia hirta var. pulcherrima Caused by Podosphaera fusca
}

\author{
Mi-Jeong Park ${ }^{1}$, Ji-Hyun Park ${ }^{1}$, Soon-Gu Lee ${ }^{2}$ and Hyeon-Dong Shin ${ }^{1 *}$ \\ ${ }^{1}$ Division of Environmental Science and Ecological Engineering, Korea University, Seoul 136-701, Korea \\ ${ }^{2}$ Department of Plant Medicine, School of Bioresources Science, Andong National University, Andong 760-749, Korea
}

(Received on March 24, 2010; Accepted on May 11, 2010)

Rudbeckia hirta var. pulcherrima (syn. R. bicolor, R. serotina), commonly known as "black-eyed Susan", is a flowering plant belonging to the Asteraceae. The plant is native to North America and was introduced to Korea for ornamental purposes in the $1950 \mathrm{~s}$; it is now naturalized and can be found growing wild here. In September 2009 , occurrence of a previously unknown powdery mildew was observed on the plants in a public park and also in a private garden in Ganghwa, Korea. The leaf surfaces of affected plants were covered with white mycelia and conidia, occasionally having a necrotic center. Leaf distortions, which often result from these infections, reduce the ornamental value of this plant. Symptoms were also observed on stems and flower petals (Fig. 1A $\&$ B). Around $30 \%$ of the plants surveyed were affected by the disease. In November 2009, plants with symptoms were also found in Namyangju and Jeju, Korea. Representative samples (KUSF24604, F24863, F24869) were deposited in Korea University.

Detailed microscopic examination of a representative sample (KUS-F24869) was made to identify the pathogen. Conidiophores were unbranched, cylindrical, $80-180 \times 9-11(-13) \mu \mathrm{m}$, composed of a basal cell with a slightly constricted base and three to eight barrel-shaped conidia formed in chains (Fig. 1C). Appressoria were poorly developed, indistinct and nipple-shaped. Conidia were ellipsoid or doliiform, 24-36 $\times 15-20 \mu \mathrm{m}$, containing distinct fibrosin bodies (Fig. 1D). No chasmothecia were found but the above characteristics are still consistent with Podosphaera fusca (Fr.) U. Braun \& Shishkoff [syn. Sphaerotheca fusca (Fr.) S. Blumer] (Braun, 1987).

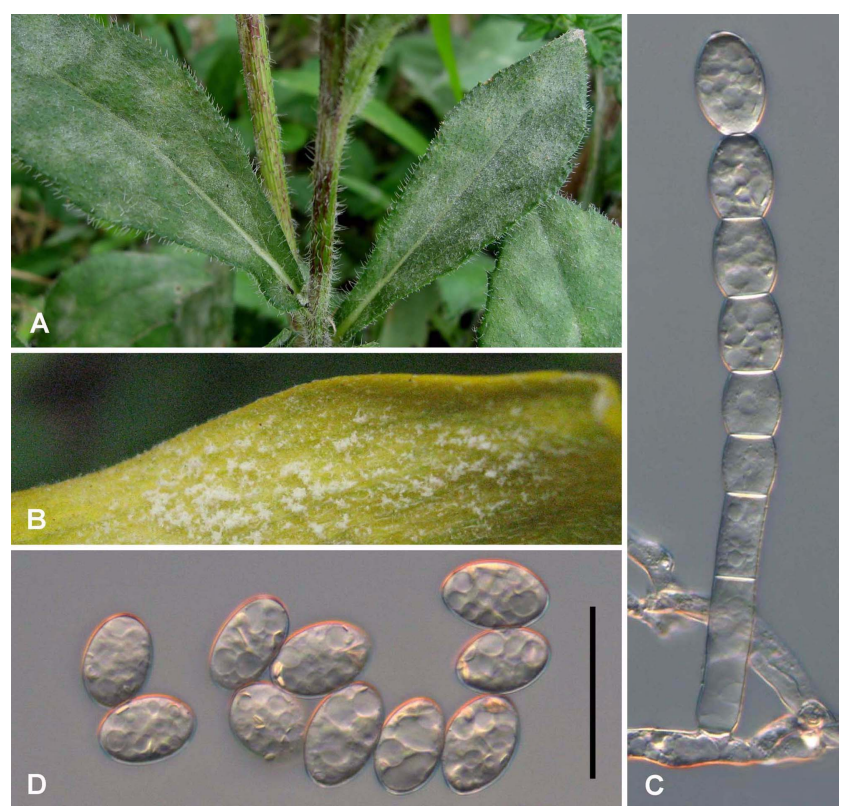

Fig. 1. Powdery mildew infections of Rudbeckia hirta var. pulcherrima caused by Podosphaera fusca. Symptoms on young leaves and stems (A) and a flower petal (B). Conidiophore (C) and conidia (D) containing conspicuous fibrosin bodies. Bar $=50 \mu \mathrm{m}$.
To confirm the identity of the causal fungus, the complete ITS region of rDNA from KUS-F24869 was amplified with primers ITS5 and P3, as described by Takamatsu et al. (2009), and directly sequenced. The resulting sequence, of $477 \mathrm{bp}$, was deposited in GenBank, with the accession number of HM004615. MEGA4 with neighbor-joining method (using Tajima-Nei model) was used to perform phylogenetic analysis. In the phylogenetic tree (Fig. 2), the ITS sequence of the fungus infecting $R$. hirta var. pulcherrima was grouped with those of three isolates of $P$. fusca retrieved from GenBank. The present isolate shared $100 \%$ sequence similarity with those of $P$. fusca from Lactuca indica and Tussilago farfara, and $99 \%$ ( 1 bp substitution and 2 bp insertion) with a Japanese isolate from $R$. hirta var. pulcherrima.

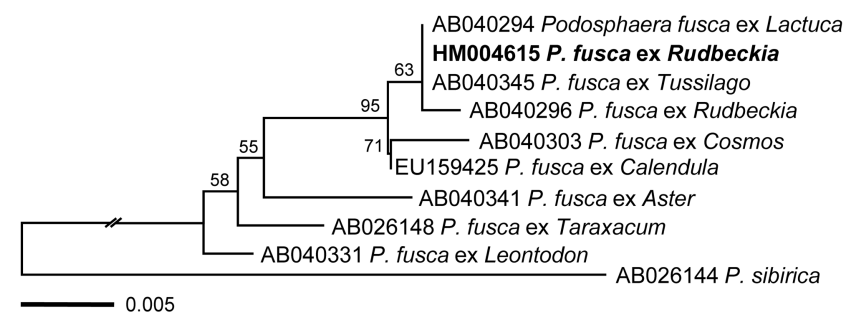

Fig. 2. Phylogenetic relationship between Podosphaera fusca on Rudbeckia hirta var. pulcherrima and some reference isolates retrieved from GenBank, inferred by neighbor-joining method using the ITS rDNA region. Numbers above the branches represent the bootstrap values. Bar $=$ Number of nucleotide substitutions per site.

Powdery mildew infections with Golovinomyces cichoracearum (syn. Erysiphe cichoracearum) have been recorded on several species of Rudbeckia from many countries (Farr and Rossman, 2010). However, powdery mildew infections with $P$. fusca (syn. $P$. fuliginea) were recorded on $R$. laciniata var. hortensis from Japan and on R. amplexicaulis from Romania (Farr and Rossman, 2010). Hirata et al. (2000) provided the first evidence that $P$. fusca is associated with $R$. hirta var. pulcherrima, by analyzing the ITS sequence of a Japanese isolate. The present work confirms this hostparasite combination, by providing consistent morphological and molecular data.

\section{References}

Braun, U. 1987. A Monograph of the Erysiphales (Powdery Mildews). Beihefte zur Nova Hedwigia 89:1-700.

Farr, D. F. and Rossman, A. Y. 2010. Fungal Databases, Systematic Mycology \& Microbiology Laboratory, ARS, USDA. Retrieved March 12, 2010, from http://nt.ars-grin.gov/fungaldatabases/

Hirata, T., Cunnington, J. H., Paksiri, U., Limkaisang, S., Shishkoff, N., Grigaliunaite, B., Sato, Y. and Takamatsu, S. 2000. Evolutionary analysis of subsection Magnicellulatae of Podosphaera section Sphaerotheca (Erysiphales) based on the rDNA internal transcribed spacer sequences with special reference to host plants. Can. J. Bot. 78:1521-1530.

Takamatsu, S., Heluta. V., Havrylenko, M. and Divarangkoon, R. 2009. Four powdery mildew species with catenate conidia infect Galium: molecular and morphological evidence. Mycol. Res. 113:117-129.

*Corresponding author (hdshin@korea.ac.kr) 